06

\title{
Получение высокопроводящих и оптически прозрачных пленок со структурой мультиграфена путем карбонизации полиимидных пленок Ленгмюра-Блоджетт
}

\author{
(C) С.И. Голоудина ${ }^{1}$, В.В. Лучинин ${ }^{1}$, В.М. Пасюта ${ }^{1}$, А.Н. Смирнов ${ }^{2}$, Д.А. Кириленко ${ }^{2,3}$, Е.Н. Севостьянов $^{1}$, \\ Г.А. Коноплев ${ }^{1}$, В.В. Андрюшкин ${ }^{1}$, В.П. Склизкова ${ }^{4}$, И.В. Гофрман ${ }^{4}$, В.М. Светличный ${ }^{4}$, В.В. Кудрявцев ${ }^{4}$ \\ ${ }^{1}$ Санкт-Петербургский государственный электротехнический университет „ЛЭТИ“, \\ Санкт-Петербург, Россия \\ ${ }^{2}$ Физико-технический институт им. А.Ф. Иофффе РАН, \\ Санкт-Петербург, Россия \\ ${ }^{3}$ Санкт-Петербургский национальный исследовательский университет информационных технологий, \\ механики и оптики (Университет ИТМО), \\ Санкт-Петербург, Россия \\ ${ }^{4}$ Институт высокомолекулярных соединений РАН, \\ Санкт-Петербург, Россия \\ E-mail: goloudina@mail.ru
}

Поступило в Редакцию 15 февраля 2019 г.

В окончательной редакции 15 февраля 2019 г.

Принято к публикации 19 февраля 2019 г.

\begin{abstract}
Впервые получены пленки мультиграфена на поверхности кварцевого стекла путем карбонизации пленок Ленгмюра-Блоджетт полиимида. На спектрах комбинационного рассеяния пленок наблюдались полосы $G, D$ и широкая полоса в области 2300-3200 $\mathrm{cm}^{-1}$, характерные для графитоподобных пленок. С помощью метода просвечивающей микроскопии показано, что пленки состоят из „стопок“ слоев с расстоянием между слоями $0.36 \mathrm{~nm}$. Поверхностное сопротивление пленок толщиной $5 \mathrm{~nm}$ составляло $1.2 \pm 0.2 \mathrm{k} \Omega$, а коэффициент пропускания был равен $87 \%$ при $\lambda=550 \mathrm{~mm}$. В ИК-области спектра коэффициент пропускания составлял $97 \%$, а в УФ-области - $70-80 \%$.
\end{abstract}

DOI: 10.21883/PJTF.2019.09.47716.17735

Несмотря на успехи в исследовании и применении графена $[1,2]$, остается актуальной проблема получения больших по площади и бездефектных слоев графена на изолирующих и полупроводниковых подложках. В настоящее время наиболее структурно совершенные пленки графена получают на поверхности кристаллов $\mathrm{SiC}$ методом сублимации. Однако области применения графена на $\mathrm{SiC}$ весьма ограничены. Для массового производства пленок графена подходит метод химического газофазного осаждения (CVD), с помощью которого на поверхности меди или никеля получают пленки графена, а затем переносят их на другие подложки с использованием полимерной пленки. Однако полученные таким образом пленки графена являются поликристаллическими и содержат дефекты в виде складок и границ между зернами, что снижает эффективность использования их в приборах нано- и оптоэлектроники. Кроме того, в пленках графена, как правило, остаются примеси металлов и полимера. В связи с этим активно ведутся работы по поиску методов, позволяющих получать структурно совершенные пленки графена непосредственно на изолирующих и полупроводниковых подложках без использования слоя металла-катализатора. Одним из подходов к решению этой проблемы является карбонизация органических соединений. В работе [3] для карбонизации использовались пленки дискотиче- ских веществ, которые наносились на кварцевую подложку методом центрифугирования. Поверхностное сопротивление полученных пленок углерода толщиной $4 \mathrm{~nm}$ составляло $15 \mathrm{k} \Omega$. В работе [4] при карбонизации пленок Ленгмюра-Блоджетт (ЛБ) полиимида (ПИ) на поверхности $\mathrm{Cu}$-подложки были получены пленки графена, однако на подложке $\mathrm{SiO}_{2} / \mathrm{Si}$ образовывались только аморфные пленки углерода. Ранее мы сообщали о получении проводящих и оптически прозрачных углеродных пленок на поверхности кварца и сапфира в результате карбонизации пленок ЛБ жесткоцепного ПИ ДФ-оТД [5]. Пленки толщиной $10 \mathrm{~nm}$ имели проводимость $\sim 400 \mathrm{~S} / \mathrm{cm}$ и коэффициент пропускания $\sim 60 \%$ при $\lambda=550 \mathrm{~nm}$.

В настоящей работе представлены результаты исследования пленок углерода, полученных карбонизацией пленок ЛБ жесткоцепного полиимида ПМ-пФ на поверхности кварцевого стекла. В качестве преполимера для получения полиимида ПМ-пФ использовалась алкиламмонийная соль полиамидокислоты (ПАК) ПМ-пФ (см. таблицу). Монослои соли ПАК переносили с поверхности воды на подложку из кварцевого стекла методом ЛБ. Для получения ПИ пленки ЛБ соли ПАК имидизовали, нагревая до температуры $400^{\circ} \mathrm{C}$. Карбонизация пленок ЛБ ПИ проводилась в вакууме $1 \mathrm{mPa}$ при температуре $1000^{\circ} \mathrm{C}$. 
Структурные формулы соли ПАК и ПИ

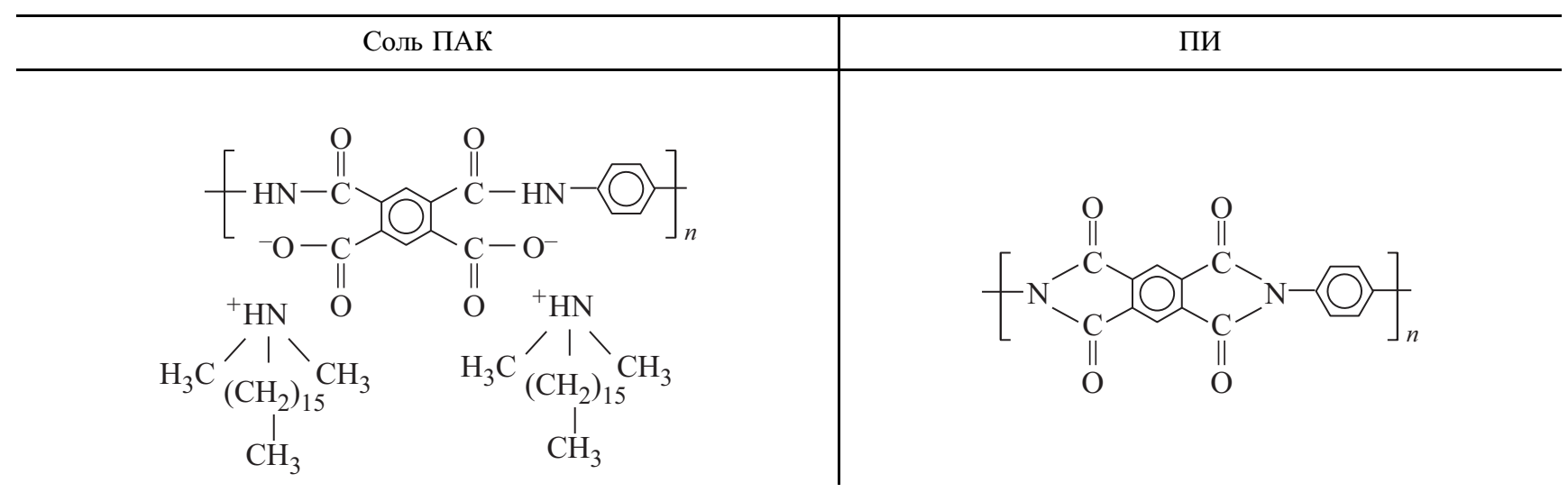
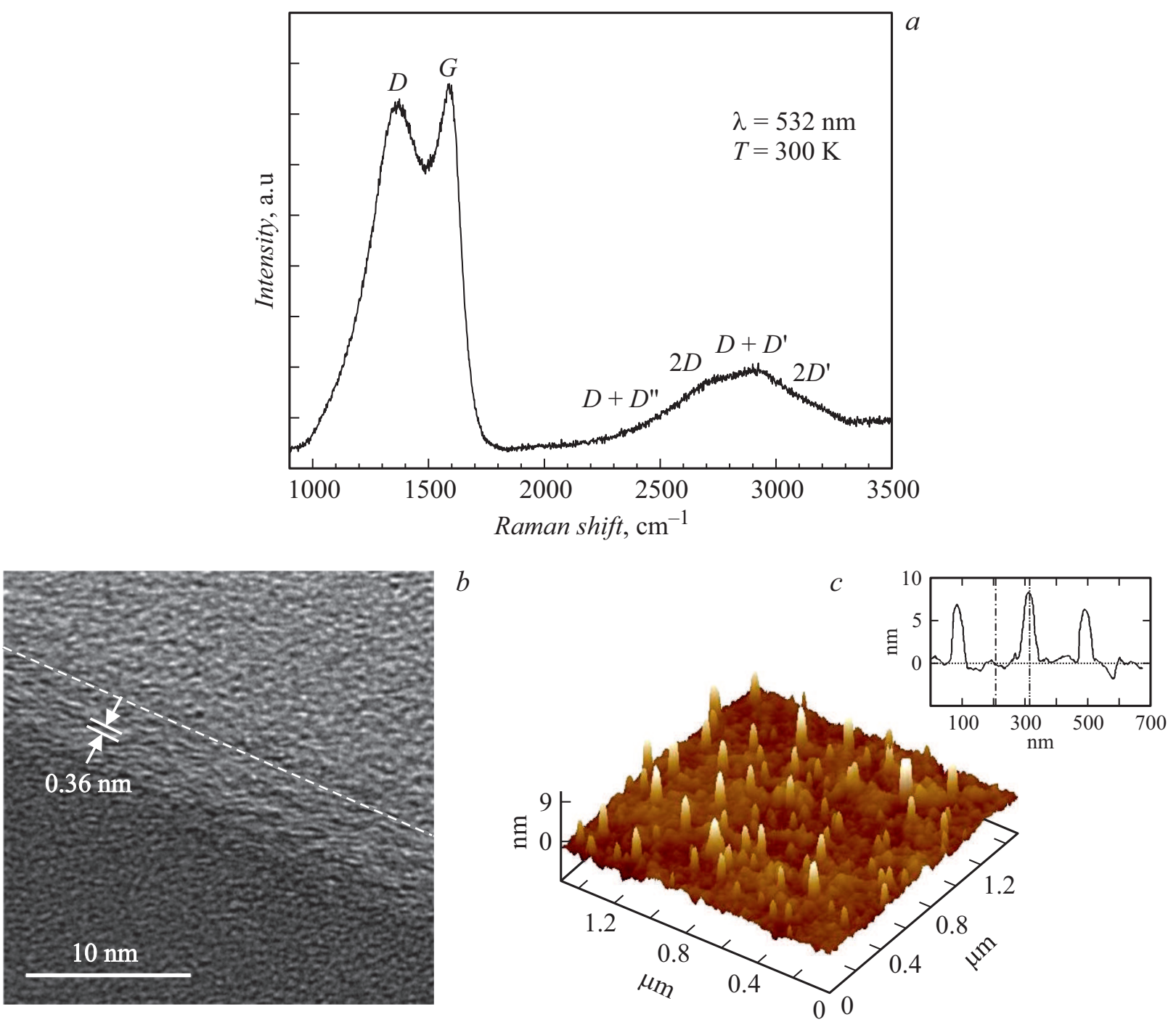

Рис. 1. КРС-спектр (a), ПЭМ-изображение поперечного среза $(b)$, АСМ-изображение поверхности $(c)$ пленок углерода, полученных в результате карбонизации при $1000^{\circ} \mathrm{C}$ пленок ЛБ полиимида (20 слоев).

На рис. 1, $a$ приведен типичный спектр комбинационного рассеяния света (КРС) пленки углерода, получен- ной в результате карбонизации пленки ПИ, содержащей 20 слоев. Для получения спектров использовался 

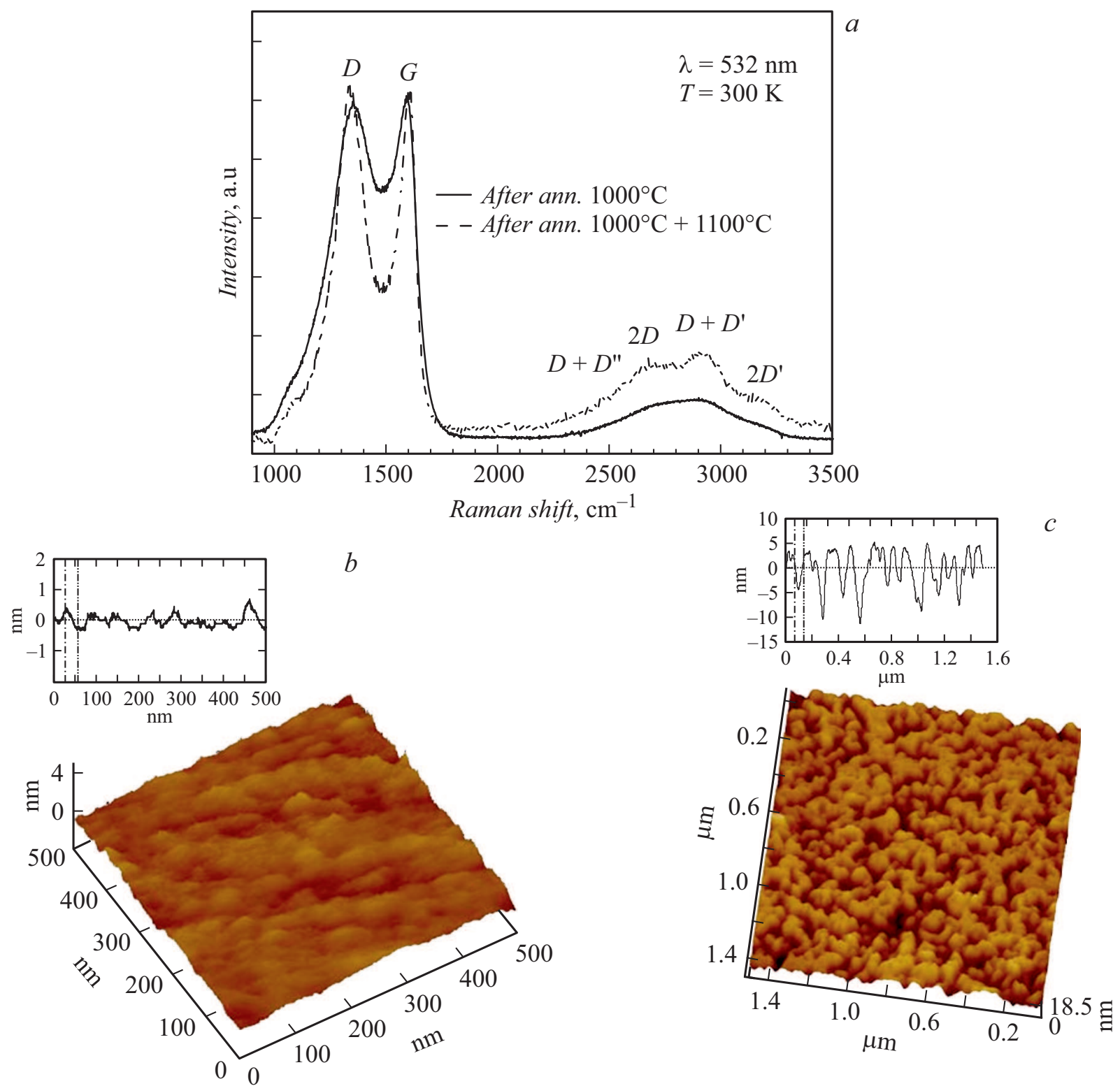

Рис. 2. Сравнение КРС-спектров $(a)$ и АСМ-изображениий поверхности пленок углерода, полученных в результате карбонизации при 1000 и $1100^{\circ} \mathrm{C}$ пленок ЛБ ПИ (10 слоев) $(b, c)$.

$\mathrm{Nd}$ :YAG-лазер с $\lambda=532 \mathrm{~nm}$. В спектре наблюдались линии $D\left(\sim 1374 \mathrm{~cm}^{-1}\right), G\left(\sim 1590 \mathrm{~cm}^{-1}\right)$ и широкая полоса в области $2300-3200 \mathrm{~cm}^{-1}$, объединяющая линии $D+D^{\prime \prime}, 2 D, D+D^{\prime}$ и $2 D^{\prime}$ (см. работу [6] и ссылки в ней). Полученный спектр является характерным для графитоподобных пленок. Полоса $G$ связана с нерезонансным рассеянием света с участием оптического фонона симметрии $E_{2 g}$, а полоса $D$ появляется в результате двойного резонансного рассеяния с участием электронных состояний из $K$ - и $K^{\prime}$-точек зоны Бриллюэна и оптического фонона симметрии $A_{1 g}$. Наличие в КРС-спектре линий второго порядка свидетельствует о формировании в пленке углерода слоев графена, обладающих дальним порядком. Структура пленок ис- следовалась с помощью просвечивающей электронной микроскопии (ПЭМ) с использованием микроскопа Jeol JEM-2100F (ускоряющее напряжение $200 \mathrm{kV}$, разрешение по точкам $0.19 \mathrm{~nm})$. Образцы для ПЭМ в геометрии поперечного сечения готовились по стандартной методике, включающей механическую шлифовку и травление ионами $\mathrm{Ar}^{+}$при энергиях $4 \mathrm{keV}$. Изображение сечения пленки (рис. $1, b)$ показывает, что она имеет толщину $5 \mathrm{~nm}$ (граница пленки указана штриховой линией) и состоит из прерывистых слоев протяженностью 5-8 nm, ориентированных приблизительно параллельно подложке. Фрагменты слоев образуют „стопки“, высота которых колеблется от 2-3 до 14 слоев, расчеты показывают, что расстояние между слоями составляет $0.36 \mathrm{~nm}$ 
(рис. $1, b)$, что близко к расстоянию между слоями в структуре графита $(0.34 \mathrm{~nm})$. Таким образом, „стопки“ слоев можно рассматривать как области со структурой мультиграфена. На некоторых участках высота „стопок“, состоящих из 14 слоев, соответствует толщине пленки $(5 \mathrm{~nm})$. Морфология пленок исследовалась методом атомно-силовой микроскопии (АСM) на микроскопе производства Vеeсо (США), модель Dimension 3100 (Nanoscope V) в полуконтактном режиме. На поверхности пленки наблюдались выступы высотой 3-7 nm и диметром $\sim 50 \mathrm{~nm}$ (рис. $1, c)$. Шероховатость пленки $\left(R_{a}\right)$ составляла $0.78 \mathrm{~nm}$.

Спектры КРС пленок углерода, полученных при карбонизации более тонких пленок ПИ (10 слоев), приведены на рис. 2, $a$. В спектре пленок углерода, полученных при $1000^{\circ} \mathrm{C}$, наблюдались линии $G, D$ и широкая полоса в области 2300-3200 $\mathrm{cm}^{-1}$, так же как и для пленок, содержащих 20 слоев. Однако положение линий $G$ и $D$ изменилось и составило $\sim 1604$ и $\sim 1355 \mathrm{~cm}^{-1}$ соответственно. Кроме того, анализ спектров показал, что изменилось соотношение интегральных интенсивностей линий $D$ и $G\left(I_{D} / I_{G}\right)$ и уменьшилась ширина на половине высоты (FWHM) линии $G$, что указывает на формирование более совершенной структуры в тонкой пленке. На АСМ-изображении поверхности пленки видно, что она состоит из доменов размером $20 \times 50 \mathrm{~nm}$, ориентированных в одном направлении и образующих „борозды“ высотой $1 \mathrm{~nm}$. При этом значение $R_{a}$ на площади $0.5 \times 0.5 \mu \mathrm{m}$ составляет всего $0.25 \mathrm{~nm}$ (рис. 2,b). Пленка ПИ, состоящая из 10 слоев, после отжига при температуре $1000^{\circ} \mathrm{C}$ вторично отжигалась при температуре $1100^{\circ} \mathrm{C}$ в течение $3 \mathrm{~min}$. После дополнительного отжига наблюдались изменения в спектре КРC (рис. 2,a): значительно уменьшились FWHМ линий $D, G$ и появилась характерная структура в области полос $D+D^{\prime \prime}, 2 D, D+D^{\prime}$ и $2 D^{\prime}$, что свидетельствует об увеличении структурной упорядоченности в пленке после отжига (см. работу [6] и ссылки в ней). Однако шероховатость поверхности пленки увеличилась, значение $R_{a}$ на площади $1.5 \times 1.5 \mu \mathrm{m}$ составило $3 \mathrm{~nm}$ (рис. 2,c).

Измерение электрофизических свойств пленок проводилось с помощью четырехзондового метода. Поверхностное сопротивление пленок углерода толщиной $5 \mathrm{~nm}$ (20 слоев) было равно $1.2 \pm 0.2 \mathrm{k} \Omega$ (объемная электропроводность $1800 \mathrm{~S} / \mathrm{cm})$, а для пленок толщиной $\sim 2.5 \mathrm{~nm}$ (10 слоев) оно составило $9.0 \mathrm{k} \Omega$ (объемная электропроводность $470 \mathrm{~S} / \mathrm{cm})$. Коэффициент пропускания пленок при $\lambda=550 \mathrm{~nm}$ независимо от их толщины составлял $87 \%$. С увеличением длины волны до $1000 \mathrm{~nm}$ коэффициент пропускания постепенно увеличивался и достигал $90 \%$, а в диапазоне длин волн $2.5-7.5 \mathrm{~nm}$ этот коэффициент был равен 97\%. В интервале длин волн 200-270 nm наблюдалось снижение коэффициента пропускания от 85 до 70\% и затем постепенное увеличение коэффициента пропускания до 78\% при $450 \mathrm{~nm}$. Для измерения коэффициента пропускания пленок в видимой и УФ-областях спектра использовался спектрофотометр Ava Spec-2048, а в ИК-области - ИК-Фурье-спектрометр Nicolet 6700 .

Полученные результаты показывают, что карбонизация пленок ЛБ ПИ является перспективным методом для получения структурно упорядоченных пленок углерода. Образование пленок со структурой мультиграфена является следствием формирования бездефектной упаковки плоских полимерных цепей в пленках ЛБ ПИ. Ранее было показано, что плотность ПИ в пленках ЛБ, состоящих из семи слоев, близка к теоретической плотности ПИ [7]. Косвенным доказательством формирования плотной укладки полимерных цепей в пленках ЛБ ПИ является возможность использования их для „герметизации“ пор размером $2 \mathrm{~nm}$ в пористом low-k материале [8].

Карбонизированные пленки ПИ могут иметь разные сферы применения, в первую очередь связанные с использованием их в качестве прозрачных электродов. Малая величина шероховатости и отсутствие складок делают их перспективными для использования в оптоэлектронных приборах, изготавливаемых на поверхности различных диэлектрических и полупроводниковых материалов, таких как $\mathrm{SiO}_{2} / \mathrm{Si}$, кварц, сапфир, $\mathrm{Si}_{3} \mathrm{~N}_{4}, h$-BN и т. п. Особенности морфологии полученных пленок позволяют говорить об эффективности их использования в сенсорах, в качестве холодных эмиттеров и ориентирующих слоев в жидкокристаллических ячейках.

\section{Финансирование работы}

Исследования методом ПЭМ выполнены с использованием оборудования федерального ЦКП „Материаловедение и диагностика в передовых технологиях“, поддержанного Министерством образования и науки РФ (уникальный идентификатор проекта RFMEFI62117X0018).

\section{Список литературы}

[1] Novoselov K..S., Fal'ko V.I., Colombo L., Gellert P.R., Schwab M.G., Kim K. // Nature. 2012. V. 490. P. 192-200. DOI: $10.1038 /$ nature 11458

[2] Ferrari A.C. // Nanoscale. 2015. V. 7. P. 4598-4810. DOI: $10.1039 / \mathrm{C} 4 \mathrm{NR} 01600 \mathrm{~A}$

[3] Wang X., Zhi L., Tsao N., Tomović Ž., Li J., Müllen K. // Angew. Chem. Int. Ed. 2008. V. 47. P. 2990-2992. DOI: 10.1002/ange.200704909

[4] Jo H.J., Lyu J.H., Ruoff R.S., Lim H., Yoon S.I., Jeong H.Y., Shin T.J., Bielawski C.W., Shin H.S. // 2D Mater. 2017. V. 4. P. 014005. https://doi.org/10.1088/2053-1583/4/014005 
[5] Голоудина С.И., Лучинин В.В., Пасюта В.М., Панов М.Ф., Севостьянов Е.Н., Гофман И.В., Склизкова В.П., Светличный В.М., Кудрявцев В.В. // Нано- и микросистемная техника. 2015. № 12. С. 32-37.

[6] Виноградов А.Я., Грудинкин С.А., Беседина Н.А., Коняхин С.В., Рабчинский М.К., Эйдельман Е.Д., Голубев В.Г. // ФТП. 2018. Т. 52. В. 7. С. 775-781.

DOI: 10.21883/FTP.2018.07.46051.8782

[7] Голоудина С.И., Лучинин В.В., Пасюта В.М., Розанов В.В., Склизкова В.П., Кудрявщев В.В., Левин А.А., Майер Д.К., Пауфлер П. // ЖПХ. 2005. Т. 78. № 9. C. $1499-1503$.

[8] Luchinin V.V., Goloudina S.I., Pasyuta V.M., Ivanov A.S., Baklanov M., Krishtab M. Method for pore sealing of porous materials using polyimide Langmuir-Blodgett film. US9492841 B2. 15.11.2016. EP2662151 (A1). 29.08.2018. 